\title{
Fracionamento de carboidratos e proteínas de gramíneas tropicais cortadas em três idades
}

[Carbohydrates and proteins fractions of tropical grasses cut at three ages]

\author{
J.F. Sá ${ }^{1}$, M.S. Pedreira ${ }^{2}$, F.F. Silva, $a^{2,6}$, P. Bonomo ${ }^{2}$, M.P. Figueiredo ${ }^{3}$, \\ D.R. Menezes ${ }^{4}$, T.B. Almeida ${ }^{5}$ \\ ${ }^{1}$ Aluna de pós-graduação - UESB - Itapetinga, BA \\ ${ }^{2}$ Universidade Estadual do Sudoeste da Bahia - Itapetinga, BA. \\ ${ }^{3}$ Universidade Estadual do Sudoeste da Bahia - Vitória da Conquista, BA. \\ ${ }^{4}$ Zootecnista \\ ${ }^{5}$ Aluno de graduação - UESB - Itapetinga-BA \\ ${ }^{6}$ Pesquisador do $\mathrm{CNPq}$

\section{RESUMO}

Avaliou-se o fracionamento dos carboidratos e das proteínas das gramíneas tropicais tifton 85 (Cynodon dactylon cv Tiffon 85), braquiária (Brachiaria brizantha cv Marandu) e tanzânia (Panicum maximum Jacq. cv Tanzânia), cortadas aos 28, 35 e 54 dias de idade. Determinaram-se os teores de matéria seca (MS), matéria orgânica (MO), proteína bruta $(\mathrm{PB})$, extrato etéreo (EE), fibra em detergente neutro corrigida para cinzas e proteína $\left(\mathrm{FDN}_{\mathrm{CP}}\right)$, fibra em detergente ácido (FDA), lignina (LIG), nitrogênio insolúvel em detergente neutro (NIDN) e nitrogênio insolúvel em detergente ácido (NIDA). Para PB determinaram-se as frações $\mathrm{A}, \mathrm{B} 1+\mathrm{B} 2$, B3 e $\mathrm{C}$, e para os carboidratos as frações $\mathrm{A}+\mathrm{B} 1, \mathrm{~B} 2$ e $\mathrm{C}$. Foi utilizado o delineamento inteiramente ao acaso, em arranjo em parcelas (gramíneas) subdivididas (idades de corte). Houve efeito significativo $(\mathrm{P}<0,05)$ da idade de corte sobre os teores de $\mathrm{MS}, \mathrm{FDN}_{\mathrm{CP}}$, NIDN e NIDA. Os teores de PB apresentaram declínio com o avanço da idade. O capim-marandu apresentou teores elevados para as frações A+B1 e B2 dos carboidratos (25,5 e 34,8\% dos carboidratos totais, respectivamente) e para as frações $\mathrm{A}$ e B1+B2 das proteínas $(28,1 \%$ aos 35 dias e 53,8\% da PB aos 28 dias, respectivamente).

Palavras-chave: forragem tropical, tifton, braquiária, tanzânia

\begin{abstract}
The carbohydrates and proteins fractions of tropical grasses Tifton 85 (Cynodon dactylon cv Tifton 85), brachiaria (Brachiaria brizantha cv Marandu), and Tanzania (Panicum maximum Jacq. cv Tanzania) were evaluated at cut ages of 28, 35, and 54 days. Contents of dry matter (DM), organic matter (OM), crude protein $(C P)$, ether extract $(E E)$, fiber in neutral detergent corrected for ashes and protein $\left(N D F_{C P}\right)$, fiber in acid detergent $(A D F)$, lignin $(L I G)$, neutral detergent insoluble nitrogen (NDIN), and acid detergent insoluble nitrogen $(A D I N)$ were determined. For $C P$, the $A, B 1+B 2$, B3, and $C$ fractions were determined. For carbohydrates, the fractions $A+B 1, B 2$, and $C$ were measured. A completely randomized split-plot design was used. Effect of cut age on DM, NDF $C P, N D I N$ and ADIN was observed. The CP contents decreased with the progress of the age for the three grasses. The Marandu grass presented high percentage of the fractions $A+B 1$ and B2 for the total carbohydrate (25.5 and 34.8\%, respectively) and of the fractions $A$ and $B 1+B 2$ for the proteins $(28.1 \% C P$ at 35 days and $53.8 \% C P$ at 28 days, respectively).
\end{abstract}

Keywords: tropical grass, brachiaria, tifton, tanzania

Recebido em 26 de março de 2009

Aceito em 30 de abril de 2010

E-mail: jacklinezoo@hotmail.com

Apoio: FABESP 


\section{INTRODUÇÃO}

No Brasil, a grande maioria das áreas de pastagens é constituída por plantas forrageiras tropicais (Corsi, 1986). Dentre as espécies mais comuns, destacam-se Panicum maximum Jacq., Brachiaria brizantha e Cynodon spp. Essas espécies são de alto potencial de produção e baixo custo (Reis, 2005), e podem produzir 26 ton/MS/ha/ano (Jank, 1995), 18 ton/MS/ha/ano (Crispim e Branco, 2002) e 16,6 ton/MS/ha/ano (Hill et al., 1993), respectivamente.

Devido às variações climáticas anuais caracterizadas por períodos de chuva e de seca, ocorre drástica variação no teor proteico e na fibra, associada à concentração de lignina nas plantas. A lignina forma uma barreira que impede a aderência microbiana e a hidrólise enzimática da celulose e da hemicelulose, indisponibilizando os carboidratos estruturais potencialmente degradáveis presentes na parede celular (Rodrigues et al., 2004).

Sniffen et al. (1992) sugeriram que, na avaliação dos alimentos, os teores de nitrogênio e de carboidratos sejam fracionados, possibilitando formular dietas que promovam perfeita sincronização entre a disponibilidade de carboidratos e nitrogênio no rúmen.

O sistema Cornell Net Carbohydrate and Protein System (CNCPS) classifica os microrganismos ruminais em dois grandes grupos: os fermentadores de carboidratos fibrosos, que utilizam amônia como fonte de $\mathrm{N}$, e os fermentadores de carboidratos não fibrosos, que utilizam tanto amônia quanto aminoácidos ou peptídeos como fonte de N. Esse sistema permite o fracionamento dos carboidratos nas frações A (açúcares simples) e B1 (amido e pectina), de rápida e média degradação ruminal, respectivamente, na fração B2 (parede celular disponível de acordo com as taxas de passagem e degradação) e na fração C (lignina) não degradada pelos microrganismos ruminais.

Este trabalho teve o objetivo de avaliar o fracionamento dos carboidratos e das proteínas de três gramíneas tropicais, capins tifton, marandu e tanzânia, colhidas em três diferentes idades.

\section{MATERIAL E MÉTODOS}

O experimento foi realizado no Campus Juvino Oliveira, da Universidade Estadual do Sudoeste da Bahia (UESB), município de Itapetinga-BA. As gramíneas avaliadas foram capim-tifton 85 (Cynodon dactylon cv Tifton 85), capim-braquiarão
(Brachiaria brizantha cv Marandu) e capimtanzânia (Panicum maximum cv Tanzânia), cultivadas isoladamente em canteiros com dimensões de 9x3m. O delineamento experimental utilizado foi o inteiramente ao acaso, em parcelas subdivididas, sendo as gramíneas localizadas nas parcelas e as idades de corte nas subparcelas. Utilizaram-se quatro canteiros (repetições) para cada espécie avaliada. Os cortes foram feitos entre dezembro de 2005 e janeiro de 2006, nas idades de 28,35 e 54 dias de rebrota, com alturas de $30 \mathrm{~cm}$ para o capim-tanzânia, $20 \mathrm{~cm}$ para o capimmarandu, e $10 \mathrm{~cm}$ para o capim-tifton 85 em relação ao nível do solo.

As amostras, pré-secas a $55^{\circ} \mathrm{C}$ em estufa de ventilação forçada durante 72 horas, foram moídas em peneira com crivos de $1 \mathrm{~mm}$ para determinação da matéria seca (MS), lignina (LIG) com ácido sulfúrico a $72 \%$, matéria mineral (MM), proteína bruta $(\mathrm{PB})$, extrato etéreo (EE), nitrogênio insolúvel em detergente neutro (NIDN) e nitrogênio insolúvel em detergente ácido (NIDA), de acordo com Silva e Queiroz (2002), fibra em detergente neutro corrigido para cinzas e proteínas $\left(\mathrm{FDN}_{\mathrm{CP}}\right)$ e fibra em detergente ácido (FDA), conforme ANKOM Fiber Analyser $\left(\mathrm{ANKOM}^{200}\right)$, citado por Holden (1999). A matéria orgânica (MO) das amostras foi obtida por diferença (100 - cinzas).

Os carboidratos totais (CT) foram calculados a partir da fórmula $\mathrm{CT}=100-(\% \mathrm{~PB}+\% \mathrm{EE}+$ \%cinzas); a fração $\mathrm{C}$ foi obtida a partir do FDN indigestível após 144 horas de incubação in situ; a fração B2, a partir da subtração da fração $\mathrm{C}$ da (FDNcp); e os carboidratos não fibrosos (CNF), a partir da fórmula: $\mathrm{CNF}=100-(\% \mathrm{~PB}+\% \mathrm{FDNcp}+$ $\% \mathrm{EE}+\% \mathrm{MM})$, de acordo com Sniffen et al. (1992). O fracionamento das proteínas foi feito de acordo com a metodologia descrita por Licitra et al. (1996), constituído de fração A, referente ao nitrogênio solúvel em ácido tricloroacético (TCA) $10 \%$; fração $\mathrm{B} 3$, determinada pela diferença entre os teores de NIDN e NIDA; e fração C, referente ao NIDA. A fração B1+B2 (proteína verdadeira de rápida e intermediária degradação) foi determinada pela diferença entre nitrogênio total (NT) e as frações $\mathrm{A}+\mathrm{B} 3+\mathrm{C}$.

Para realização das análises estatísticas, foi utilizado o SAEG (Sistema..., 2001).

\section{RESULTADOS E DISCUSSÃO}

Os teores de MS e MO das gramíneas cortadas em diferentes idades são apresentados na Tab. 1. 
Houve interação $(\mathrm{P}<0,05)$ gramíneas versus idades de corte para o teor de MS, e observou-se aumento linear crescente, mas em proporções diferentes, segundo a gramínea, com o avanço da idade de corte. O capim-tifton foi o que apresentou os maiores teores de MS em todas as idades. Em relação aos teores de MO, não houve diferença $(\mathrm{P}>0,05)$ com o aumento da idade. $\mathrm{O}$ capim-tanzânia apresentou a menor média dessa variável $(89,6 \%)$, e as outras duas gramíneas não diferiram entre si.

Tabela 1. Teores de matéria seca (MS) e matéria orgânica (MO) das gramíneas tifton 85, marandu e tanzânia, em três idades de corte (dias)

\begin{tabular}{lcccccc}
\hline Gramínea & 28 dias & 35 dias & 54 dias & Média & Equação de regressão & $\mathrm{r}^{2}$ \\
\hline Tifton 85-MS(\%) & $18,2 \mathrm{a}$ & $20,5 \mathrm{a}$ & $27,9 \mathrm{a}$ & & $\hat{\mathrm{Y}}=7,48+0,37 \mathrm{x}$ & 0,99 \\
Marandu-MS(\%) & $13,3 \mathrm{~b}$ & $15,6 \mathrm{~b}$ & $20,5 \mathrm{~b}$ & & $\hat{\mathrm{Y}}=5,84+0,27 \mathrm{x}$ & 0,97 \\
Tanzânia-MS(\%) & $14,1 \mathrm{~b}$ & $17,1 \mathrm{~b}$ & $20,8 \mathrm{~b}$ & & $\hat{\mathrm{Y}}=7,80+0,25 \mathrm{x}$ & 0,96 \\
\hline Tifton 85-MO (\%) & 91,7 & 90,7 & 92,7 & $91,7 \mathrm{a}$ & & \\
Marandu-MO (\%) & 91,1 & 89,9 & 92,4 & $91,1 \mathrm{a}$ & \\
Tanzânia-MO (\%) & 90,1 & 88,9 & 89,9 & $89,6 \mathrm{~b}$ & \\
Média & 91,0 & 89,8 & 91,6 & & & \\
\hline
\end{tabular}

Médias na coluna seguidas de letras minúsculas distintas diferem entre si $(\mathrm{P}<0,05)$ pelo teste Tukey.

$\mathrm{CV} \mathrm{MS}=4,4 \% ; \mathrm{CV} \mathrm{MO}=0,80 \%$.

Estes resultados demonstram que o intervalo entre cortes é um fator de manejo que contribui para determinar a produção e a qualidade da forragem. Sabe-se que, com o envelhecimento da planta, o teor de umidade se reduz, resultando em maior produção de MS. Valadares Filho et al. (2006) encontraram, para os capins tifton, marandu e Tanzânia, teores de MO de 92,3\%, $90,6 \%$ e $90,9 \%$ da MS, respectivamente.
Não houve interação $(\mathrm{P}>0,05)$ gramíneas versus idades de corte para os teores de PB e NIDN (Tab. 2). Para as três gramíneas, houve efeito significativo da idade de corte $(\mathrm{P}<0,05)$ sobre o teor de PB. Esse efeito pode ser explicado porque, à medida que a planta avança no estágio de maturação, ocorre diminuição do teor proteico em função do aumento do teor de fibra (Rodrigues et al., 2004).

Tabela 2. Teores de proteína bruta (PB) e de nitrogênio insolúvel em detergente neutro (NIDN) das gramíneas tifton 85 , marandu e tanzânia, em três idades de corte (dias)

\begin{tabular}{lcccccc}
\multicolumn{1}{c}{ Gramínea } & 28 dias & 35 dias & 54 dias & Média & $\begin{array}{c}\text { Equação de } \\
\text { regressão }\end{array}$ & $\mathrm{r}^{2}$ \\
\hline $\begin{array}{l}\text { Tifton } 85-\mathrm{PB} \\
\text { (\% na MS) }\end{array}$ & 15,5 & 10,7 & 6,9 & 11,0 & \\
$\begin{array}{l}\text { Marandu-PB } \\
\text { (\% na MS) }\end{array}$ & 14,8 & 10,3 & 6,7 & 10,6 & \\
$\begin{array}{l}\text { Tanzânia-PB } \\
\text { (\% na MS) }\end{array}$ & 14,7 & 10,6 & 5,5 & 10,3 & & \\
Média & 15,0 & 11,0 & 6,4 & & $\hat{\mathrm{Y}}=22,97-0,31 \mathrm{x}$ & 0,95 \\
\hline $\begin{array}{l}\text { Tifton } 85-N I D N \\
(\% \text { na NT) }\end{array}$ & 39,0 & 46,2 & 47,8 & $44,3 \mathrm{a}$ & & \\
$\begin{array}{l}\text { Marandu-NIDN } \\
\text { (\% na NT) }\end{array}$ & 21,2 & 26,6 & 30,1 & $26,0 \mathrm{~b}$ & & \\
$\begin{array}{l}\text { Tanzânia-NIDN } \\
(\% \text { na NT) }\end{array}$ & 34,9 & 46,6 & 47,2 & $42,9 \mathrm{a}$ & & \\
Média & 31,7 & 39,8 & 41,7 & & $\hat{\mathrm{Y}}=25,16+0,32 \mathrm{x}$ & 0,68 \\
\hline
\end{tabular}

Médias na coluna seguidas de letras minúsculas distintas diferem entre si $(\mathrm{P}<0,05)$ pelo teste Tukey. MS: matéria seca; $\mathrm{NT}$ : nitrogênio total. $\mathrm{CV} \mathrm{PB}=8,8 \% ; \mathrm{CV} \mathrm{NIDN}=7,3 \%$. 
Em todas as gramíneas, os teores de NIDN aumentaram linearmente com o avanço da idade de corte. Malafaia et al. (1997) encontraram valores de NIDN de 43,9\% da PB para o capimtifton 85 , e de $45,4 \%$ da PB para a Brachiaria brizantha. Entre as gramíneas, o marandu apresentou a menor média de NIDN, 26,0\%, enquanto o tifton 85 e o tanzânia foram semelhantes, 47,8 e $42,9 \%$, respectivamente.
Os valores de $\mathrm{FDN}_{\mathrm{CP}}$, FDA e LIG encontram-se na Tab. 3. Houve interação gramíneas versus idade de corte $(\mathrm{P}<0,05)$ apenas para a $\mathrm{FDN}_{\mathrm{CP}}$. $\mathrm{A}$ medida que aumentou a idade de corte, ocorreu aumento crescente nos teores de $\mathrm{FDN}_{\mathrm{CP}}$, mas os aumentos foram em proporções diferentes, segundo a gramínea.

Tabela 3. Teores de fibra em detergente neutro corrigido para cinzas e proteína $\left(F D N_{C P}\right)$, fibra em detergente ácido (FDA) e lignina (LIG) das gramíneas tifton 85, marandu e tanzânia, em três idades de corte (dias)

\begin{tabular}{lcccccc}
\hline \multicolumn{1}{c}{ Gramínea } & 28 & 35 & 54 & Média & Equação de regressão & $\mathrm{r}^{2}$ \\
\hline $\begin{array}{l}\text { Tifton } 85-F D N_{\mathrm{CP}} \\
(\% \text { na MS) }\end{array}$ & $70,3 \mathrm{a}$ & $76,3 \mathrm{a}$ & $80,0 \mathrm{a}$ & & $\hat{\mathrm{Y}}=62,45+0,34 \mathrm{x}$ & 0,85 \\
$\begin{array}{l}\text { Marandu-FDN } \\
\text { (\% na MS) }\end{array}$ & $64,6 \mathrm{~b}$ & $66,0 \mathrm{c}$ & $75,8 \mathrm{~b}$ & & $\hat{\mathrm{Y}}=51,28+0,45 \mathrm{x}$ & 0,98 \\
$\begin{array}{l}\text { Tanzânia-FDN } \\
\text { (\% na MS) }\end{array}$ & $66,7 \mathrm{ab}$ & $72,1 \mathrm{~b}$ & $74,8 \mathrm{~b}$ & & $\hat{\mathrm{Y}}=60,51+0,27 \mathrm{x}$ & 0,81 \\
\hline $\begin{array}{l}\text { Tifton 85-FDA (\% na } \\
\text { MS) }\end{array}$ & 43,5 & 45,6 & 48,1 & $45,7 \mathrm{~b}$ & & \\
$\begin{array}{l}\text { Marandu-FDA } \\
\text { (\% na MS) }\end{array}$ & 42,5 & 44,3 & 49,6 & $45,5 \mathrm{~b}$ & & \\
$\begin{array}{l}\text { Tanzânia-FDA } \\
\text { (\% na MS) }\end{array}$ & 47,8 & 49,4 & 52,9 & $50,1 \mathrm{a}$ & & \\
Média & 44,6 & 46,5 & 50,2 & 47,1 & $\hat{\mathrm{Y}}=38,86+0,21 \mathrm{x}$ & 0,99 \\
\hline $\begin{array}{l}\text { Tifton 85-LIG } \\
\text { (\% na MS) }\end{array}$ & 4,9 & 3,9 & 5,3 & $4,7 \mathrm{ab}$ & & \\
$\begin{array}{l}\text { Marandu-LIG } \\
\text { (\% na MS) }\end{array}$ & 4,7 & 4,3 & 4,5 & $4,5 \mathrm{~b}$ & & \\
$\begin{array}{l}\text { Tanzânia-LIG } \\
\text { (\% na MS) }\end{array}$ & 4,7 & 5,1 & 5,5 & $5,1 \mathrm{a}$ & & \\
Média & 4,8 & 4,4 & 5,1 & & & \\
\hline
\end{tabular}

Médias na coluna seguidas de letras minúsculas distintas diferem entre si $(\mathrm{P}<0,05)$ pelo teste Tukey. MS: matéria seca. $\mathrm{CV} \mathrm{FDN} \mathrm{CP}_{\mathrm{C}}=2,8 \%$; CV FDA $=4,7 \%$; $\mathrm{CV} \mathrm{LIG}=12,9 \%$.

Aos 28 dias de idade, o capim-tifton apresentou valores médios de $\mathrm{FDN}_{\mathrm{CP}}$ mais elevados que o marandu e semelhantes ao tanzânia; aos 35 dias, o tifton 85 foi superior ao Tanzânia, e este superior ao marandu; e aos 54 dias, o tifton, novamente, apresentou o melhor resultado. Os valores de FDNcp, que variaram de 66,7 a $74,8 \%$ para o tanzânia, foram semelhantes aos observados por Machado et al. (1998), cujo valor médio de FDN foi de 71,1\%. Barbosa e Euclides (1997), ao estudarem o valor nutritivo de três ecotipos de $P$. maximum, entre eles o capimtanzânia, obtiveram teor médio de FDN de $72,9 \%$ na MS, e Malafaia et al. (1997) valores de FDNcp de 73,6 e 73,5\% da MS para capim-tifton e Brachiaria brizantha, respectivamente, cortados aos 60 dias após a rebrota. Houve semelhança de valores obtidos neste estudo e os observados na literatura.

Segundo Mertens (1992), o consumo de FDN acima de 1,2\% do peso corporal (PC) limita o consumo por mecanismos físicos. Ítavo et al. (2002) relataram que o consumo de FDN, em dietas exclusivas com volumosos, é maior que $1,2 \%$ do PC. Esses autores verificaram valores do consumo do FDN do feno de capim-tifton 85 para novilhos Nelores na fase de recria de até $1,9 \%$ do PC. No presente trabalho, as gramíneas apresentaram, aos 28 dias, os menores valores de FDNcp, e isto pôde propiciar consumo de MS de 2,7; 2,9 e 2,8\% do PC, para os capins tifton, marandu e tanzânia, respectivamente, considerando um consumo máximo de FDN de $1,9 \%$ do PC. 
Foi observado aumento nos valores de FDA com o avanço da idade, e o capim-tanzânia foi o que apresentou os maiores teores dessa variável. Resultados semelhantes foram relatados por Cecílio Filho et al. (2002), que observaram valores médios de 42,3, 42,0 e 44,9\% de FDA para os capins tifton, braquiarão e tanzânia, respectivamente, cortados em intervalo de 35 dias durante o período chuvoso.

A lignina não foi influenciada pela idade de corte ( $\mathrm{P}>0,05)$, e o capim-tifton apresentou o menor teor em relação às demais gramíneas aos 35 dias, mas não há uma explicação plausível para tal. De acordo com Migita e Kawamura (1944), parte considerável da fração de lignina é potencialmente solúvel na solução de ácido sulfúrico, o que pode ter subestimado o teor de lignina nas amostras avaliadas. Hernandez et al. (2002) relataram valores de lignina de 6,8 e 3,9\% da MS, respectivamente, para o feno de capimtifton, coletado com cinco semanas de idade, e para o capim-braquiarão, coletado no início das águas, com 45 dias de idade.

Os valores de EE, CT e CNF estão expressos na Tab. 4. Houve interação $(\mathrm{P}<0,05)$ gramíneas versus idade apenas para o EE, e ocorreu efeitos linear crescente para o capim-tifton, mas não com os outros dois capins, com avanço da idade de corte. Esse comportamento pode ter sido em função da contaminação pela cera cuticular. De acordo com Oliveira e Prates (2000), os nalcanos são compostos orgânicos que compõem a cera das plantas e podem causar variação na proporção dos constituintes da cera, dependendo da idade das folhas e, possivelmente, também da parte da planta coletada (Horn et al., 1964).

Para os CT, houve aumento linear nos teores de CT com o avanço da idade, para as três gramíneas. O capim-tifton apresentou valores mais altos que o marandu e semelhantes ao tanzânia. Segundo Balsalobre et al. (2003), a variação na qualidade dessa fração interfere diretamente na disponibilidade de energia para o ruminante, ou seja, o avanço da idade da planta causa aumento nos constituintes da parede celular, diminuindo, assim, os teores de CNF e, consequentemente, o fornecimento de energia de rápida degradação para os microrganismos ruminais. Esses autores encontraram, para amostras de capim-tanzânia, em pastejo simulado, valores de CT entre 74 e $78 \%$.

Tabela 4. Teores de extrato etéreo (EE), carboidratos totais (CT) e carboidratos não fibrosos (CNF) das gramíneas tifton 85 , marandu e tanzânia, em três idades de corte (dias)

\begin{tabular}{|c|c|c|c|c|c|c|}
\hline Gramínea & 28 & 35 & 54 & Média & Equação de regressão & $\mathrm{r}^{2}$ \\
\hline $\begin{array}{l}\text { Tifton 85-EE } \\
\text { (\% na MS) }\end{array}$ & $1,6 \mathrm{c}$ & $1,7 \mathrm{~b}$ & $3,1 b$ & & $\hat{Y}=-0,35+0,06 x$ & 0,98 \\
\hline $\begin{array}{l}\text { Marandu-EE } \\
\text { (\% na MS) }\end{array}$ & $4,1 \mathrm{a}$ & $4,4 \mathrm{a}$ & $4,2 \mathrm{a}$ & & & \\
\hline $\begin{array}{l}\text { Tanzânia-EE } \\
\text { (\% na MS) }\end{array}$ & $2,7 b$ & $2,2 b$ & $3,1 b$ & & & \\
\hline Médias & 2,8 & 2,8 & 3,5 & & & \\
\hline $\begin{array}{l}\text { Tifton } 85-\mathrm{CT} \\
\text { (\% na MS) }\end{array}$ & 74,7 & 77,3 & 82,7 & $78,2 \mathrm{a}$ & & \\
\hline $\begin{array}{l}\text { Marandu-CT } \\
\text { (\% na MS) }\end{array}$ & 72,3 & 75,0 & 81,5 & $76,2 b$ & & \\
\hline $\begin{array}{l}\text { Tanzânia-CT } \\
\text { (\% na MS) }\end{array}$ & 72,8 & 76,1 & 81,4 & $76,8 \mathrm{ab}$ & & \\
\hline Média & 73,2 & 76,1 & 81,8 & & $\hat{\mathrm{Y}}=64,43+0,32 \mathrm{x}$ & 0,99 \\
\hline $\begin{array}{l}\text { Tifton 85-CNF } \\
\text { (\% na MS) }\end{array}$ & 4,4 & 2,0 & 2,7 & $3,0 \mathrm{c}$ & & \\
\hline $\begin{array}{l}\text { Marandu- CNF } \\
\text { (\% na MS) }\end{array}$ & 7,7 & 9,0 & 5,7 & $7,4 \mathrm{a}$ & & \\
\hline $\begin{array}{l}\text { Tanzânia CNF } \\
\text { (\% na MS) }\end{array}$ & 6,1 & 4,7 & 6,6 & $5,5 b$ & & \\
\hline Média & 6,1 & 5,2 & 5,0 & & $\hat{Y}=2,69+0,07 x$ & 0,13 \\
\hline
\end{tabular}

Médias na coluna seguidas de letras minúsculas distintas diferem entre si $(\mathrm{P}<0,05)$ pelo teste Tukey.

MS: matéria seca. $\mathrm{CV} \mathrm{EE}=10,6 \%$; $\mathrm{CV} \mathrm{CT}=1,7 \%$; $\mathrm{CV} \mathrm{CNF}=27,9 \%$. 
O capim-marandu apresentou os maiores teores de CNF. Hernandez et al. (2002) encontraram valores de 9,8 e $8,1 \%$ da MS de CNF para o capim-braquiarão e para o capim-tifton, respectivamente, cortados aos 45 dias.

Os resultados das frações de carboidratos são apresentados na Tab. 5. Houve interação idade versus gramínea $(\mathrm{P}<0,05)$ para as frações de carboidratos A+B1, B2 e C. A porção dos carboidratos de rápida degradação ruminal $(\mathrm{A}+\mathrm{B} 1)$, os quais correspondem aos carboidratos solúveis e ao amido, apresentou valores entre 16,5 e $25,5 \%$ dos CT, e houve efeito linear decrescente para essa fração com o avanço da idade, mas em proporções diferentes, segundo a gramínea, fato esperado, pois os componentes estruturais da parede celular aumentam à medida que a planta se desenvolve, em detrimento dos carboidratos não fibrosos (Van Soest, 1994). Observaram-se valores mais altos de $\mathrm{A}+\mathrm{B} 1$ para os capins marandu e tanzânia. Os teores mais baixos da fração $A+B 1$ se justificam no caso do capim-tifton, pelo fato de os valores da fibra em detergente neutro terem sido relativamente altos, de 70 a $80 \%$ da MS, conforme sugeriram Malafaia et al. (1998) e Gonçalves et al. (2003). Balsalobre et al. (2003) verificaram valores semelhantes aos deste trabalho para o capimtanzânia, 15,4 e 23,2\% dos CT. De acordo com Vieira et al. (2000), as gramíneas tropicais raramente apresentam teores de carboidratos da fração A+B1 acima de $20 \%$ dos CT.

Tabela 5. Frações de carboidratos, A+B1, B2 e C, das gramíneas tifton 85, marandu e tanzânia, em três idades de corte (dias)

\begin{tabular}{lccccc}
\hline Gramínea & 28 & 35 & 54 & Equação de regressão & $\mathrm{r}^{2}$ \\
\hline $\begin{array}{l}\text { Tifton 85- A + B1 } \\
\text { (\% do NT) }\end{array}$ & $22,1 \mathrm{~b}$ & $18,2 \mathrm{c}$ & $16,5 \mathrm{~b}$ & $\hat{\mathrm{Y}}=26,30-0,19 \mathrm{x}$ & 0,78 \\
$\begin{array}{l}\text { Marandu-A + B1 } \\
\text { (\% do NT) }\end{array}$ & $25,5 \mathrm{a}$ & $25,0 \mathrm{a}$ & $19,7 \mathrm{a}$ & $\hat{\mathrm{Y}}=32,56-0,23 \mathrm{x}$ & 0,97 \\
$\begin{array}{l}\text { Tanzânia-A + B1 } \\
\text { (\% do NT) }\end{array}$ & $24,2 \mathrm{a}$ & $21,2 \mathrm{~b}$ & $20,5 \mathrm{a}$ & $\hat{\mathrm{Y}}=26,65-0,12 \mathrm{x}$ & 0,68 \\
\hline $\begin{array}{l}\text { Tifton 85- B2 } \\
\text { (\% do NT) }\end{array}$ & $41,5 \mathrm{a}$ & $45,6 \mathrm{a}$ & $44,9 \mathrm{a}$ & $\hat{\mathrm{Y}}=40,29+0,09 \mathrm{x}$ & 0,34 \\
$\begin{array}{l}\text { Marandu- B2 } \\
\text { (\% do NT) }\end{array}$ & $34,8 \mathrm{~b}$ & $36,6 \mathrm{~b}$ & $44,6 \mathrm{a}$ & $\hat{\mathrm{Y}}=23,68+0,38 \mathrm{x}$ & 0,99 \\
$\begin{array}{l}\text { Tanzânia- B2 } \\
\text { (\% do NT) }\end{array}$ & $35,7 \mathrm{~b}$ & $35,3 \mathrm{~b}$ & $34,6 \mathrm{~b}$ & $\hat{\mathrm{Y}}=36,86-0,04 \mathrm{x}$ & 0,99 \\
\hline $\begin{array}{l}\text { Tifton 85-C } \\
\text { (\% do NT) }\end{array}$ & $11,0 \mathrm{a}$ & $13,4 \mathrm{~b}$ & $21,3 \mathrm{~b}$ & $\hat{\mathrm{Y}}=-0,3+0,40 \mathrm{x}$ & 0,99 \\
$\begin{array}{l}\text { Marandu-C } \\
\text { (\% do NT) }\end{array}$ & $11,8 \mathrm{a}$ & $12,9 \mathrm{~b}$ & $17,2 \mathrm{c}$ & $\hat{\mathrm{Y}}=5,84+0,21 \mathrm{x}$ & 0,99 \\
$\begin{array}{l}\text { Tanzânia-C } \\
\text { (\% do NT) }\end{array}$ & $12,9 \mathrm{a}$ & $19,6 \mathrm{a}$ & $26,3 \mathrm{a}$ & $\hat{\mathrm{Y}}=0,78+0,48 \mathrm{x}$ & 0,93 \\
\hline
\end{tabular}

Médias na coluna seguidas de letras minúsculas distintas diferem entre si $(\mathrm{P}<0,05)$ pelo teste Tukey. NT: nitrogênio total. $\mathrm{CV} \mathrm{A}+\mathrm{B} 1=6,0 \% ; \mathrm{CV} \mathrm{B} 2=5,1 \% ; \mathrm{CV} \mathrm{C}=7,5 \%$.

Com relação aos carboidratos fibrosos potencialmente digestíveis, fração B2, os capins tifton e marandu apresentaram comportamento linear crescente com o avanço da idade, e o tanzânia comportamento inverso. O tifton foi o que apresentou maiores teores da fração B2 aos 28 e 35 dias, semelhantes aos do marandu aos 54 dias de rebrota. Moraes et al. (2006) relataram valores de 46,9\% da fração B2 (\% de CT), em pastagem diferida de Brachiaria brizantha, e Malafaia et al. (1997), valores de 32,9\% da PB para Brachiaria brizantha com 60 dias de rebrota.

A fração C apresentou comportamento linear crescente, mas em proporções diferentes, segundo a gramínea, com o avanço na idade de corte (Tab. 5), o que pode ser atribuído ao aumento na fração de hemicelulose e celulose indigestível da parede celular. Segundo Van Soest (1994), a fração indigestível dos carboidratos totais tende a aumentar com o 
avanço da maturidade da planta. Resultados semelhantes ao deste estudo foram observados por Malafaia et al. (1998), os quais encontraram níveis crescentes para os teores da fração C, 16, 18,4 e $18,9 \%$ dos CT, para amostra do pastejo simulado de capim-tanzânia em diferentes estações do ano.

Os resultados encontrados para as frações de proteína $\mathrm{A}, \mathrm{B} 1+\mathrm{B} 2$, B3 e C são apresentados na Tab. 6. Não houve efeito da idade de corte $(\mathrm{P}>0,05)$ sobre a fração A. Balsalobre et al. (2003) determinaram teores entre 18 a $28 \%$ para a fração A do capim-tanzânia em pastejo simulado. Em geral, os valores da literatura são semelhantes aos encontrados neste estudo. Segundo Russell et al. (1992), fontes de nitrogênio não proteico (NNP) são fundamentais para o bom funcionamento ruminal, pois os microrganismos ruminais, fermentadores de carboidratos estruturais, utilizam amônia como fonte de nitrogênio. Todavia, altas proporções de NNP podem resultar em perdas nitrogenadas, se houver a falta do esqueleto de carbono prontamente disponível para a síntese de proteína microbiana.

Houve interação idade versus gramínea para as frações $\mathrm{B} 1+\mathrm{B} 2$. O avanço da idade reduziu linearmente, mas em proporções diferentes, segundo a gramínea, os teores das frações B1+B2. Segundo Balsalobre et al. (2003), a fração B1 tem pouca importância em gramíneas forrageiras, pois, normalmente, representa valores menores que $10 \%$ do total da proteína bruta.

Tabela 6. Frações de proteínas, A, B1+B2, B3 e C, das gramíneas tifton 85, marandu e tanzânia, em três idades de corte (dias)

\begin{tabular}{|c|c|c|c|c|c|c|}
\hline Gramínea & 28 & 35 & 54 & Média & Equação de regressão & $\mathrm{r}^{2}$ \\
\hline $\begin{array}{l}\text { Tifton } 85-\mathrm{A} \\
(\% \text { do NT) }\end{array}$ & 25,3 & 28,7 & 23,3 & $25,7 \mathrm{a}$ & & \\
\hline $\begin{array}{l}\text { Marandu-A } \\
\text { (\% do NT) }\end{array}$ & 24,9 & 28,1 & 25,1 & $26,0 \mathrm{a}$ & & \\
\hline $\begin{array}{l}\text { Tanzânia-A } \\
\text { (\% do NT) }\end{array}$ & 28,4 & 19,51 & 16,49 & $21,5 b$ & & \\
\hline Médias & 26,2 & 25,4 & 21,6 & & & \\
\hline $\mathrm{CV} \%$ & 13,6 & & & & & \\
\hline $\begin{array}{l}\text { Tifton } 85-\mathrm{B} 1+\mathrm{B} 2 \\
(\% \text { do NT) }\end{array}$ & $35,6 \mathrm{~b}$ & $25,1 b$ & $28,9 \mathrm{~b}$ & & $\hat{Y}=36,15-0,16 x$ & 0,17 \\
\hline $\begin{array}{l}\text { Marandu- B1+B2 } \\
(\% \text { do NT) }\end{array}$ & $53,8 \mathrm{a}$ & $45,3 \mathrm{a}$ & $39,4 \mathrm{a}$ & & $\hat{Y}=65,74-0,50 x$ & 0,87 \\
\hline $\begin{array}{l}\text { Tanzânia- B1+B2 } \\
(\% \text { do NT) }\end{array}$ & $36,7 b$ & $38,8 \mathrm{a}$ & $33,5 b$ & & $\hat{Y}=42,37-0,16 x$ & 0,61 \\
\hline $\begin{array}{l}\text { Tifton } 85-\mathrm{B} 3 \\
(\% \text { do NT) }\end{array}$ & 29,9 & 34,6 & 33,7 & $32,7 \mathrm{a}$ & & \\
\hline $\begin{array}{l}\text { Marandu- B3 } \\
\text { (\% do NT) }\end{array}$ & 11,6 & 15,0 & 21,4 & $16,0 \mathrm{c}$ & & \\
\hline $\begin{array}{l}\text { Tanzânia- B3 } \\
\text { (\% do NT) }\end{array}$ & 24,4 & 33,4 & 29,1 & $29,0 b$ & & \\
\hline Média & 22,0 & 27,7 & 28,1 & & $\hat{Y}=18,45+0,19 x$ & 0,56 \\
\hline $\begin{array}{l}\text { Tifton } 85-\mathrm{C} \\
(\% \text { do NT) }\end{array}$ & $9,1 \mathrm{a}$ & $11,7 \mathrm{a}$ & $14,1 b$ & & $\hat{Y}=4,69+0,18 x$ & 0,93 \\
\hline $\begin{array}{l}\text { Marandu- C } \\
(\% \text { do NT) }\end{array}$ & $9,7 \mathrm{a}$ & $11,7 \mathrm{a}$ & $12,9 b$ & & $\hat{\mathrm{Y}}=7,15+0,11 \mathrm{x}$ & 0,85 \\
\hline $\begin{array}{l}\text { Tanzânia- C } \\
(\% \text { do NT) }\end{array}$ & $10,6 a$ & $13,2 \mathrm{a}$ & $18,2 \mathrm{a}$ & & $\hat{\mathrm{Y}}=2,95+0,28 \mathrm{x}$ & 0,99 \\
\hline
\end{tabular}

Médias na coluna seguidas de letras minúsculas distintas diferem entre si $(\mathrm{P}<0,05)$ pelo teste Tukey.

NT: nitrogênio total. CV A=13,6\%; CV B1+B2=12,6\%; CV B3=9,5\%; CV C $=11,0 \%$. 
De acordo com Brennecker (2007), os valores observados para as frações B1 e B2 para amostra de pastejo simulado da Brachiaria brizantha foram de $16 \%$ e $24,5 \%$ da $\mathrm{PB}$, ou seja, esses valores somados são de $40,5 \%$ para as frações B1+B2 da PB. Segundo Winter et al. (1964) e Sniffen et al. (1992), a fração B1 + B2, por apresentar rápida taxa de degradação ruminal em relação à fração B3, tende a ser extensivamente degradada no rúmen, contribuindo para o atendimento dos requisitos de nitrogênio dos microrganismos ruminais, porém a rápida proteólise no rúmen dessas frações pode levar ao acúmulo de peptídeos e permitir o seu escape para os intestinos, uma vez que a utilização de peptídeos é considerada limitante à degradação de proteínas.

Para a fração B3, não houve interação significativa de idade versus gramínea $(\mathrm{P}>0,05)$. $\mathrm{O}$ capim-tifton apresentou os teores mais altos; o tanzânia, os intermediários; e o marandu, os mais baixos. Os avanços da idade das gramíneas aumentaram linearmente os teores da fração de lenta degradação (B3). Essa fração é representada pelas extensinas, proteínas ligadas à parede celular, portanto apresenta lenta taxa de degradação, sendo principalmente digerida nos intestinos. Diante desse fato, torna-se necessária, durante o período de transição, a utilização de suplementação com fontes ricas nas frações B1+B2, como o farelo de soja e o milho em grão (Valadares Filho et al., 2006), para animais em pastejo, com o objetivo de atender às necessidades da síntese proteica microbiana, pois, nesse período, as forrageiras, além de mostrarem declínio do seu teor proteico, apresentam maior teor das frações B3 e C e menor de $\mathrm{B} 1+\mathrm{B} 2$.

Dependendo dos objetivos de ganhos almejados pelo produtor, pode-se, também, utilizar a suplementação proteica durante o período das águas. A exigência de PB para mantença e ganho de peso de $1,5 \mathrm{~kg} / \mathrm{dia}$ de novilhos com $300 \mathrm{~kg}$ de peso corporal (PC) é de 994g/dia, segundo o NRC (Nutrient..., 1996). Considerando o capimmarandu como exemplo, aos 28 dias de idade, essa gramínea propiciaria consumo máximo de MS de 2,5\% do PC, levando-se em conta a sua composição de FDN e o limite máximo de consumo de FDN de 1,6\% do PC, segundo Ítavo et al. (2002). Já aos 54 dias de idade, o consumo máximo de MS seria de $2,1 \%$ do PC. O consumo absoluto de MS do capim-marandu seria de $7,5 \mathrm{~kg}$ e $6,3 \mathrm{~kg}$ de MS aos 28 e 54 dias de rebrota, respectivamente, o que exige que as dietas contenham 13,2 e $15,8 \%$ de $\mathrm{PB}$ para atender às exigências de mantença e ganhos de $1,5 \mathrm{~kg}$ de PC/dia (994g de PB/dia).

O teor de PB do capim-marandu aos 28 e 54 dias de rebrota foi de 14,8 e $6,7 \%$, respectivamente. Para altas taxas de ganho de peso, dietas exclusivas de gramíneas podem suprir as exigências apenas em idades muito jovens $(<28$ dias), pois permitem alto consumo e apresentam alto teor proteico. No período chuvoso, gramíneas manejadas para pastejo com descanso acima de 28 dias de rebrota podem não suprir as exigências requeridas para elevados ganhos de peso, portanto, em algumas situações, recomenda-se a suplementação proteica mesmo nesse período, dependendo do objetivo de ganho.

Ao contrário da fração B3, a fração C apresentou efeito linear decrescente com aumento da idade de corte. O comportamento das gramíneas foi semelhante, exceto aos 54 dias, quando a fração C do capim-tanzânia foi mais alta do que a dos outros dois capins.

\section{CONCLUSÕES}

O declínio nos teores de proteína bruta com avanço da idade sugere que a época de corte é importante para garantir bons teores de proteína bruta nos capins, sendo 28 dias a idade recomendada para as categorias de animais mais exigentes, em que as gramíneas apresentaram média de $15 \%$ de $\mathrm{PB}$. O corte aos 35 dias pode ser recomendado para categorias menos exigentes. Considerando o fracionamento proteico e de carboidratos, a forrageira que apresenta as melhores características é o capimmarandu, pois pode garantir melhor sincronismo da fermentação entre os carboidratos e a proteína no rúmen e, consequentemente, promover melhor crescimento microbiano. Vale salientar que os capins tifton 85 e tanzânia podem ter apresentado resultados mais baixos que o capimmarandu por apresentarem ciclos de desenvolvimento diferenciado, por isso sugerem manejo diferenciado para que deles se consiga melhor aproveitamento. 


\section{REFERÊNCIAS BIBLIOGRÁFICAS}

BALSALOBRE, M.A.A.; CORSI, M.; SANTOS, P.M. et al. Composição química e fracionamento do nitrogênio e dos carboidratos do Tanzânia irrigado sob três níveis de resíduo pós-pastejo. Rev. Bras. Zootec., v.32, p.519-528, 2003.

BARBOSA, R.A.; EUCLIDES, V.P.B. Valores nutritivos de três ecotipos de Panicum maximum. In: REUNIÃO ANUAL DA SOCIEDADE BRASILEIRA DE ZOOTECNIA, 34., 1997, Juiz de Fora. Anais... Juiz de Fora: SBZ, 1997. p.5355 .

BRENNECKER, K. Fracionamento de carboidratos e proteínas e a predição da proteína bruta e suas frações e das fibras em detergente neutro e ácido de Brachiaria brizanta cv. Marandu por uma rede neural artificial, 2007. 138f. Tese. (Doutorado) - Faculdade de Zootecnia e Engenharia de Alimentos, Universidade de São Paulo, São Paulo.

CECILIO FILHO, V.S.; RODRIGUES, L.R.A.; SILVIA, H.V. et al. Produção e valor nutritivo de dez gramíneas forrageiras na região Noroeste do Estado de São Paulo. Acta Sci., v.24, p.13771384, 2002.

CORSI, M. Potencial das pastagens para a produção de leite. In: PEIXOTO, A. M.; MOURA, J.C.; FARIA, V.P. (Eds). Bovinocultura Leiteira: fundamentos da exploração racional. Piracicaba: FEALQ, 1986. p.147-154.

CRISPIM, S.M.A.; BRANCO, O.D. Aspectos gerais das braquiárias e suas características na sub-região da Nhecolândia, Pantanal, MS. Corumbá: Embrapa Pantanal, 2002. (Boletim de Pesquisa e Desenvolvimento, 33).

GONÇALVES, G.D.; SANTOS, G.T.; JOBIM, C.C. et al. Determinação do consumo, digestibilidade e frações proteicas e de carboidratos do feno de Tifton 85 em diferentes idades de corte. Rev. Bras. Zootec., v.32, p.804$813,2003$.

HERNANDEZ, F.I.L.; VALADARES FILHO, S.C.; PAULINO, M.F. et al. Avaliação da composição de vários alimentos e determinação da cinética ruminal da proteína, utilizando o método de produção de gases e amônia in vitro. Rev. Bras. Zootec., v.31, p.243-255, 2002.
HILL, G.M.; GATES, R.N.; BURTON, G.W. Forage quality and grazing steer performance from Tifton 85 and Tifton 78 bermudagrass pastures. J. Anim. Sci., v.71, p.3219-3225, 1993.

HOLDEN, L.A. Comparison of methods of in vitro dry matter for feeds. J. Dairy Sci., v.82, p.1791-1794, 1999.

HORN, D.H.S., KRANZ, Z.H., LAMBERTON, J.A. The composition of Eucalyptus and some other leaf waxes. Aust J. Chem., v.17, p.464-476, 1964.

ÍTAVO, L.C.V.; VALADARES FILHO, S.C.; SILVA, F.F. et al. Consumo, degradabilidade ruminal e digestibilidade aparente de fenos de gramíneas do gênero Cynodon e rações concentradas utilizando indicadores internos. Rev. Bras. Zootec., v.31, suppl., p.1024-1032, 2002.

JANK, L. Melhoramento e seleção da variedade de Panicum maximum. In. SIMPÓSIO SOBRE MANEJO DE PASTAGEM, 12., 1995, Piracicaba. Anais... Piracicaba: FEALQ, 1995. p.21-58.

LICITRA, G.; HERNANDEZ, T.M.; VAN SOEST, P.J. Standardization of procedures for nitrogen frations of ruminant feeds. Anim. Feed Sci. Technol., v.57, p.347-358, 1996.

MACHADO, A.O.; CECATO, U.; MIRA, R.T. et al. Avaliação da composição química e digestibilidade in vitro da matéria seca de cultivares e acessos de Panicum maximum Jacq. sob duas alturas de corte. Rev. Bras. Zootec., v.27, p.1057-1063, 1998.

MALAFAIA, P.A.M.; VALADARES FILHO, S.C.; VIEIRA, R.A.M. et al. Determinação das frações que constituem os carboidratos totais e da cinética ruminal da fibra em detergente neutro de alguns alimentos para ruminantes. Rev. Bras. Zootec., v.27, p.790-796, 1998.

MALAFAIA, P.A.M.; VALADARES FILHO, S.C.; VIEIRA, R.A.M. et al. Determinação e cinética ruminal das frações proteicas de alguns alimentos para ruminantes. Rev. Bras. Zootec., v.26, p.1243-1251, 1997.

MERTENS, D.R. Análise da fibra e sua utilização na avaliação de alimentos e formulação de rações. In: SIMPÓSIO INTERNACIONAL DE RUMINANTES, 1992, Lavras. Anais... Lavras: SBZ, 1992. p.188-219. 
MIGITA, W.; KAWAMURA, I. Chemical analysis of wood. J. Agric. Chem. Soc. Jpn., v.20, p.384, 1944.

MORAES, E.H.B.K.; PAULINO, M.F.; ZERVOUDAKIS, J.T. et al. Associação de diferentes fontes energéticas e proteicas em suplementos múltiplos na recria de novilhos mestiços sob pastejo no período da seca. Rev. Bras. Zootec., v.35, p.914-920, 2006.

NUTRIENT requirements of beef cattle. 7.ed. Washington, DC: National Academy of Sciences, 1996.

OLIVEIRA, D.E.; PRATES, E.R. Utilização dos componentes da cera das plantas, em especial os n-alcanos, em estudos de nutrição de ruminantes. Cienc. Rural, v.30, p.549-557, 2000.

REIS, S.T. Fracionamento e degradabilidade Ruminal de proteínas Carboidradatos de forrageiras do Gênero Cynodon. 2005. 85f. Dissertação (Mestrado) - Escola Superior de Agricultura de Lavras, Lavras.

RODRIGUES, A.L.P.; SAMPAIO, I.B.M.; CARNEIRO, J.C. et al. Degradabilidade in situ da matéria seca de forrageiras tropicais obtidas em diferentes épocas de corte. Arq. Bras. Med. Vet. Zootec., v.56, p.658-664, 2004.

RUSSELL, B.J.; O'CONNOR, J.D.; FOX, D.J. et al. A net carbohydrate and protein system for evaluation cattle diets: ruminal fermentation. $J$. Dairy Sci., v.70, p.3551-3581, 1992.
SILVA, D.J.; QUEIROZ, A.C. Análise de alimentos: métodos químicos e biológicos. 3.ed. Viçosa: UFV, 2002. 235p.

SISTEMA para análises estatísticas - SAEG. Viçosa: UFV, 2001. 301p.

SNIFFEN, C.J.; O'CONNOR, D.J.; VAN SOEST, P.J. et al. A net carbohydrate and protein system for evaluating cattle diets: carbohydrate and protein availability. J. Anim. Sci., v.70, p.3562-3577, 1992.

VALADARES FILHO, S.C.; PAULINO, P.V.R.; MAGALHÃES, K.A. Exigências nutricionais de zebuínos e tabelas de composição de alimentos BR - Corte. Viçosa: UFV, 2006.

VAN SOEST, P.J. Nutritional ecology of the ruminant. 2.ed. New York: Cornell University, 1994.

VIEIRA, R.A.M.; PEREIRA, J.C.; MALAFAIA, P.A.M. Fracionamento e cinética de degradação in vitro dos compostos nitrogenados da extrusa de bovinos a pasto. Rev. Bras. Zootec., v.29, p.880-888, 2000.

WINTER, K.A.; JOHNSON, R. R.; DEHORITY, B.A. Metabolism of urea nitrogen by mixed cultures of rumen bacteria grown on cellulose. J. Dairy Sci., v.47, p.793-797, 1964. 